\title{
The quadriceps stretch reflex in human spasticity
}

\author{
DAVID BURKE ${ }^{1}$, J. D. GILLIES ${ }^{2}$, AND JAMES W. LANCE \\ From the Division of Neurology, The Prince Henry Hospital, Sydney, and the School of Medicine, Universi \\ of New South Wales, Australia
}

The similarity of decerebrate rigidity in the cat and human spasticity has been noted frequently since the initial observation of Sherrington (1897). Walshe $(1919,1929)$ considered the two conditions to be physiologically identical, although spasticity 'is but a fractional expression of decerebrate rigidity'. More recently Brodal (1962) and Rushworth (1964) have referred to this similarity. Brodal stated: 'It is unfortunate that the experimentally produced condition in animals which appears to correspond to spasticity in man has been termed decerebrate rigidity. However, this discrepancy in nomenclature should not prevent us from recognizing the essential identity of the facts behind the two terms.'

The characteristics of the stretch reflex in decerebrate rigidity have been investigated by Liddell and Sherrington (1924), and amplified by Granit (1958) and Matthews (1958, 1959). These workers have shown that reflex tension is proportional to extension, so that, in the words of Liddell and Sherrington, 'so long as the stretch increases, the reflex continues to increase'. This property of the decerebrate stretch reflex clearly differs from human spasticity in which hypertonicity melts away as stretch increases (clasp-knife phenomenon).

Since the papers of McCouch, Deering, and Stewart (1950) and Granit (1950), the clasp-knife phenomenon has been attributed to autogenic inhibition from Golgi tendon organs. More recently it has been speculated that the secondary spindle ending may play a part (Granit, 1964; Granit and Kellerth, 1967).

The present study analyses the characteristics of the stretch reflex in the quadriceps of the spastic human in order to clarify these points.

\section{MATERIALS AND METHODS}

Nineteen patients were studied. All had spasticity of one or both lower limbs, and on clinical testing all exhibited clasp-knife hypertonicity. One of the 19,

${ }^{1}$ Commonwealth Postgraduate Scholar and Adolph Basser Research Fellow in Neurology.

${ }^{2}$ Research Scholar of the National Health and Medical Research Council of Australia. paraplegic due to an angioma of the spinal cord, wat examined three months before and shortly after des veloping a complete cord lesion, confirmed at lamine\& tomy. There were nine other purely spinal patients, of whom three had clinically complete cord lesions. Four other patients suffered from multiple sclerosis, one fro pseudobulbar palsy, and one from familial spastic paraplegia. Two patients were hemiplegic from cerebrof vascular disease, and one from a glial cyst of the premoto: cortex.

The first patients were studied in the supine position with the leg over the end of the couch so that it coufah be flexed fully at the knee. Later it was found nofie convenient to examine the patient prone. The elecfro myogram (EMG) induced by passive flexion of the 190 joint was recorded with surface electrodes at $15 \mathrm{~cm}$ apart over the quadriceps muscle. The proximal electrode was positioned slightly lateral of centre avoid recording from the adductor muscles. The electro myogram was integrated (time constant $0.2 \mathrm{sec}$ ) andthe direct EMG was monitored on an oscilloscope to en⿳亠丷⿵冂⿱十口犬f that the recording was artefact-free.

A goniometer was used to measure knee joint angte and its output was differentiated (time constant 2 mseg to produce a reading of angular velocity. The direct EMG, integrated EMG, knee joint angle, and angula velocity were recorded simultaneously on a four-channe Offner Dynograph. In addition, the joint angle was displayed on an oscilloscope so that the examiner coult accurately reproduce a given angle during the courst of the examination.

In all patients the stretch reflex fatigued to a varyin degree, but a relatively stable basal level could bé reached after which observations were recorded.

The conversion of joint angle into millimetres $\frac{3}{\alpha+9}$ stretch and of velocity from degrees/sec to $\mathrm{mm} / \mathrm{sec}$ was calculated in the following way. In each of three normal subjects, the knee joint was radiographed is six different joint positions. For successive positions the change in joint angle (in degrees) and the movement of the patella (in $\mathrm{mm}$ ) were measured with correction for distortion by the beam, and each point plotted on graph of change in angle against change in lengt After unlocking of the knee joint it was found that res lationship was linear, such that for each $1.7^{\circ}$ of angular movement, the muscle was stretched approximate $1 \mathrm{~mm}$.

The calculated line of best fit for the EMG: velocit relationship was determined by regression analysis 


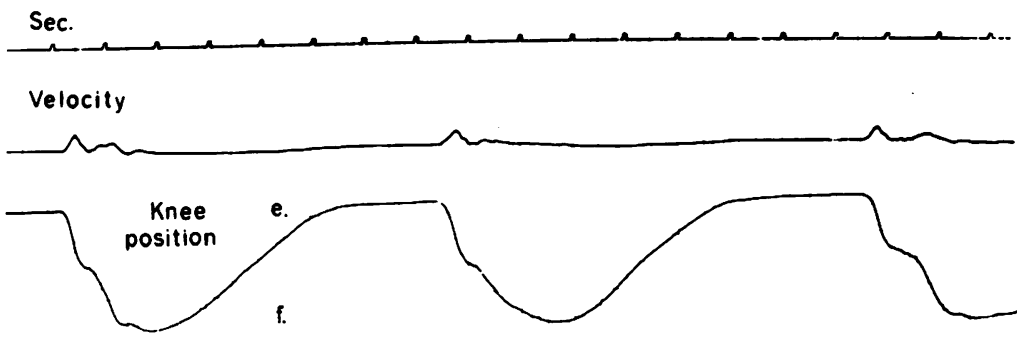

Tension

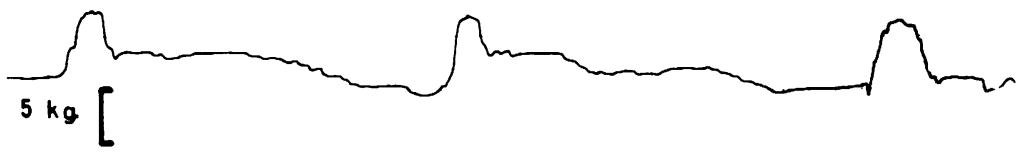

E.M.G.

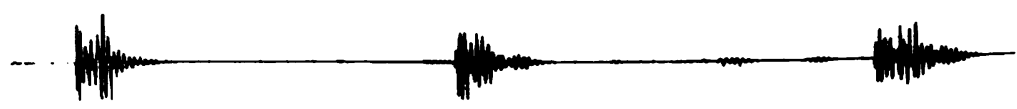

FIG. 1. The spastic stretch reflex and the clasp-knife phenomenon. Quadriceps EMG was elicited by stretching muscle from the extended position of the knee joint to $90^{\circ}$ flexion. Velocity of stretch is illustrated, together with joint position and muscle tension (as estimated by force exerted by the examiner on a transducer at the ankle). The stretch reflex is felt by the examiner as a 'catch' in the movement and may be seen in the tension, goniometer, and velocity records. The subsequent subsidence of the stretch reflex completes the clasp-knife phenomenon.

of all points, excluding those points representing a velocity below the minimum at which EMG activity was obtained. The minimal velocity for production of a stretch reflex was taken as the intercept of the line of best fit on the velocity axis.

\section{RESULTS}

THE STRETCH REFLEX IN SPASTICITY In all patients, resistance to passive flexion of the knee could be felt by the examiner to develop abruptly during the movement, and then to melt away, thus producing a clasp-knife effect (Fig. 1). During any flexion movement, once the resistance had faded away it did not recur, and with the leg flexed $90^{\circ}$ at the knee the stretch reflex was absent or barely apparent, even though it had been hyperactive at more extended positions. In extreme cases the knee jerk became pendular when tested with the knee flexed (Fig. 2). The stretch reflex did not return as long as flexion was maintained. In one patient, suffering from multiple sclerosis, the clasp-knife phenomenon fatigued with time, but a stretch reflex persisted and was then most marked with the knee flexed at $90^{\circ}$. This patient was the only exception to the basic pattern described above.
In all patients, the degree of spasticity diminished with repeated examination of the stretch reflex until a basal level was reached. In two patients, reflex resistance to passive stretch disappeared almost completely as testing continued.

VELOCITY DEPENDENCE The magnitude of the stretch reflex (as measured by surface EMG) augmented linearly as the velocity of passive knee

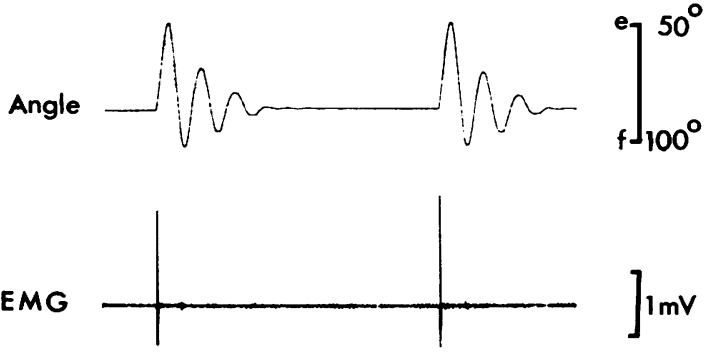

FIG. 2. Pendular knee jerk recorded in a spastic subject with the knee flexed at $90^{\circ}$, demonstrating complete suppression of the tonic stretch reflex. 


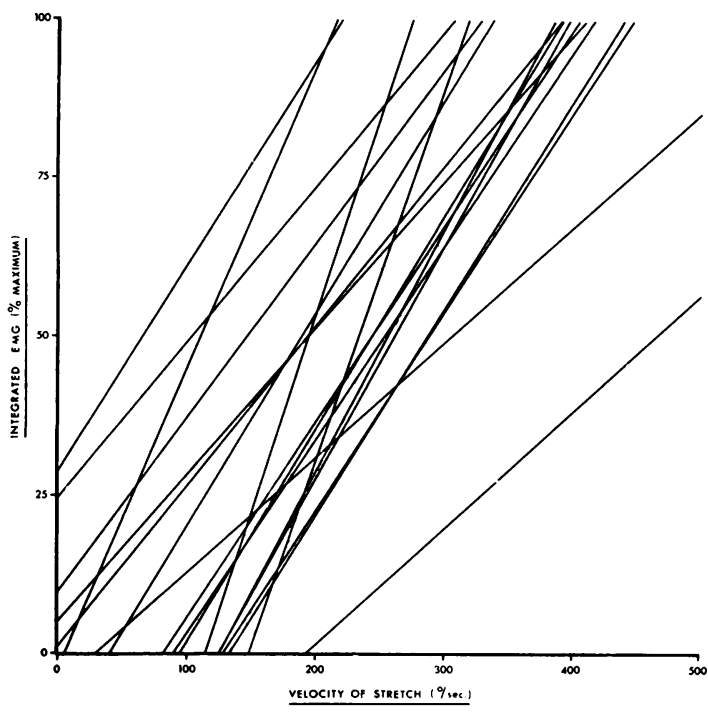

FIG. 3. Velocity-dependence of the stretch reflex. Each line represents the calculated line of best fit of multiple recordings in each of 18 patients. In all cases the movements were commenced from full extension. EMG is expressed as a percentage of the maximum EMG for that patient.

flexion increased. This relationship is illustrated in Fig. 3 in which the line of best fit, calculated from multiple readings, is plotted for each subject. In each case the flexion movement commenced from full extension. A linear relationship was also found when the movement was started with the knee joint partly flexed.

From Fig. 3 it can be seen that in five subjects spasticity was so intense that even slow movements produced a stretch reflex. In all other patients, it was possible to calculate a minimal velocity of stretch below which no stretch reflex could be recorded. This value varied according to the level of spasticity from 5 to $193 \% \mathrm{sec}$. By the method previously outlined this can be translated into a minimal linear velocity ranging from $3 \mathrm{~mm} / \mathrm{sec}$ to $113 \mathrm{~mm} / \mathrm{sec}$. As the movement was commenced from a progressively more flexed position, this minimal velocity increased and the slope of the calculated line of best fit decreased (Fig. 4).

LENGTH DEPENDENCE With one exception previously mentioned, it was found that, for a constant velocity of flexion, the stretch reflex diminished in amplitude when the stretching movement was started with the knee joint partly flexed. The greater the initial degree of flexion, the lower the reflex EMG response became (Fig. 5). This relationship was

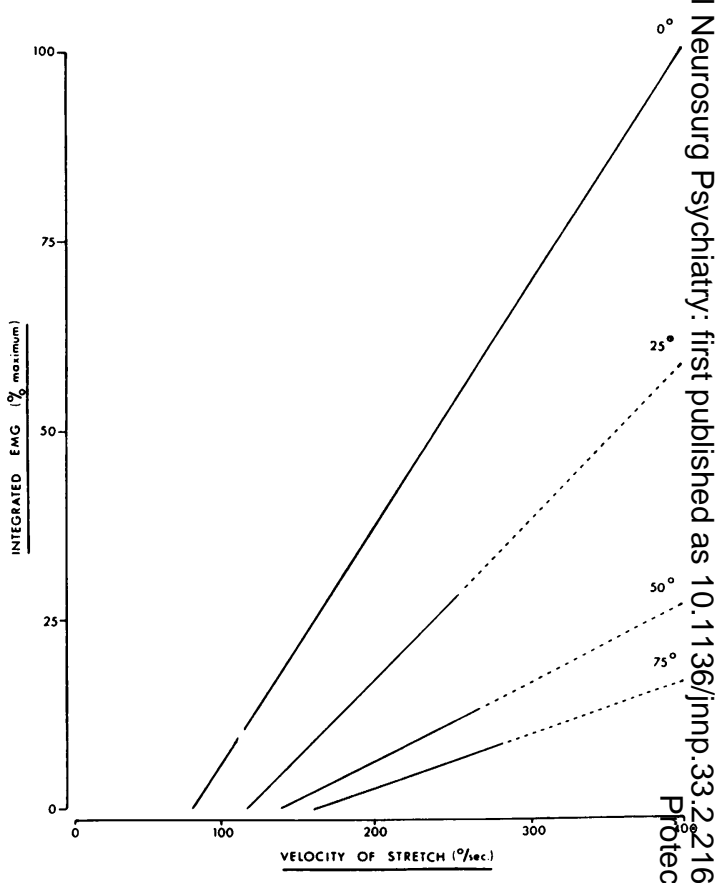

FIG. 4. Minimal velocity required to elicit a stre $\mathbb{R}_{x}$ reflex. Each line represents the calculated line of best fit for each starting angle $\left(0^{\circ}, 25^{\circ}, 50^{\circ}, 75^{\circ}\right)$. For the more flexed starting positions, each line of best fit has beet projected as a broken line past the maximum veloet attained for that position. The minimal velocity requixedo to produce a stretch reflex increases as the stretching movement commences from a more flexed joint position. In addition the slope of the line of best fit becomes less Thus a greater velocity is required to produce a stretch reflex, and less EMG is produced by any given velocity.

Time

Velocity

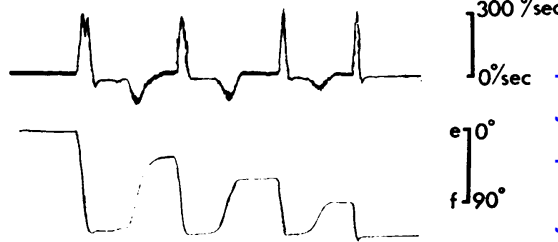

seconds

rime

Angle

gle

\section{Integrated \\ EMG}

EMG
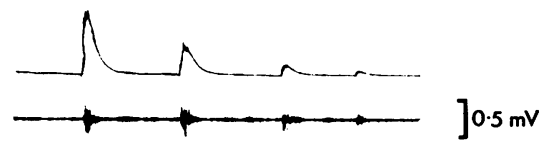

FIG. 5. Position-dependence of the stretch reflex with constant velocity of movement. The initial run starts from full extension and the fourth run starts from 9090 flexion. Velocity is constant throughout $\left(320^{\circ} / \mathrm{sec}\right)$. The stretch reflex diminishes progressively as the movementw is commenced from a more flexed position. 


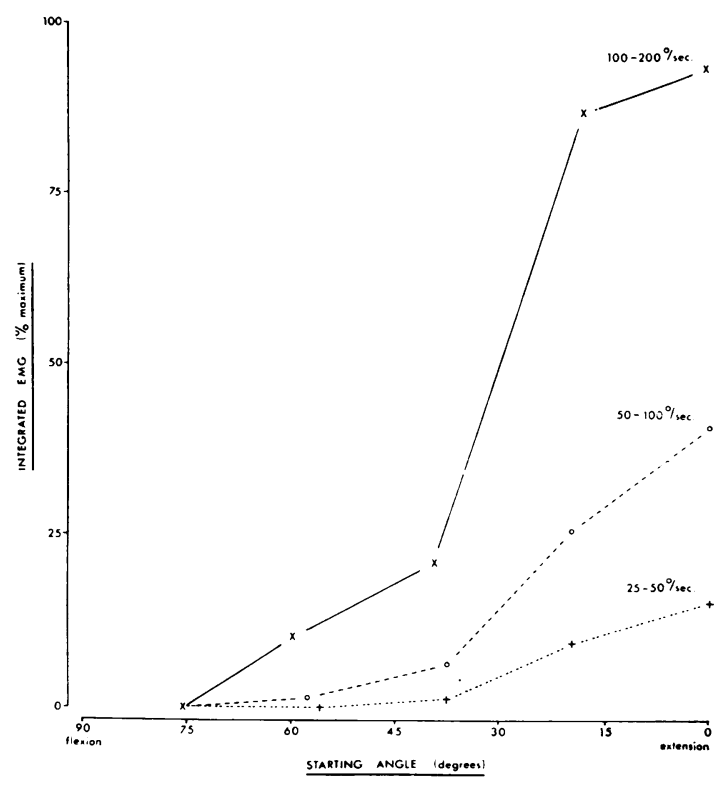

FIG. 6. Position-dependence of the stretch reflex with varying velocities of movement. Three runs, each with a different velocity range, showing that as movement begins from a more flexed position less EMG is produced. This graph shows position-dependence within each run, and velocity-dependence at any joint position.

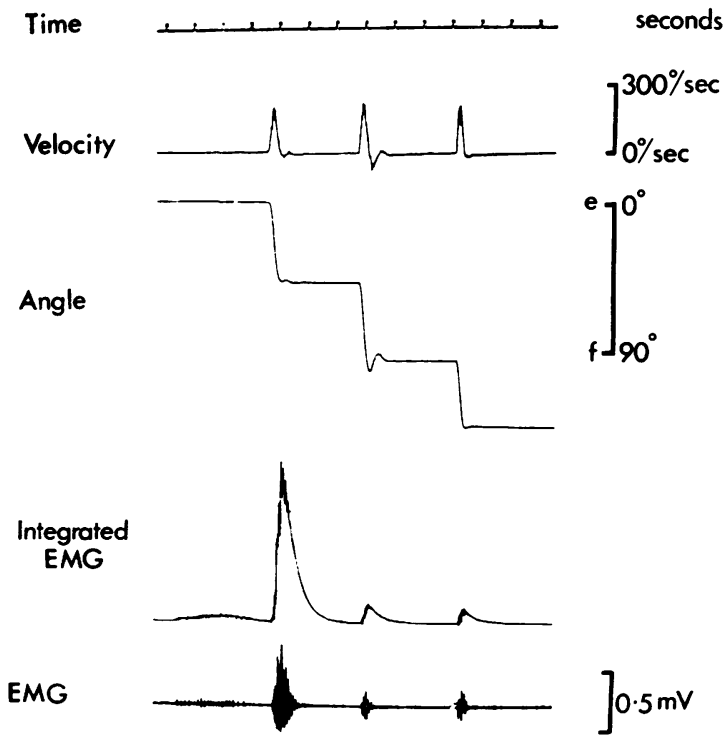

FIG. 7. Position-dependence of the stretch reflex with movement of equal length. Same as Fig. 5, except that the length of the flexion movement is the same in each instance. found to hold for groups of velocities within the range 0 to $500 \%$ sec. (Fig. 6). The reduction in the stretch reflex when starting from a flexed position was not the result of a shorter stretch since it was observed when total stretch was constant for each position (Fig. 7). That this relationship was independent of fatiguing of the stretch reflex can be seen from Fig. 8 in which A, B, and C represent successive runs at comparable velocities. Runs $\mathbf{A}$ and $\mathbf{B}$ both illustrate position dependence, although the stretch reflex had fatigued in $B$. In run $C$ no stretch reflex was obtained.

To establish whether this position-dependent suppression of the stretch reflex arose from knee joint afferents, the latter were blocked by ischaemia in five patients. A sphygmomanometer cuff was placed over the most distal part of the thigh, with the pressure maintained at $200 \mathrm{~mm} \mathrm{Hg}$ for between 30 and 45 minutes, until joint proprioception at the knee was abolished or grossly impaired. Although spasticity was reduced, a clasp-knife phenomenon could still be obtained, and position-dependent

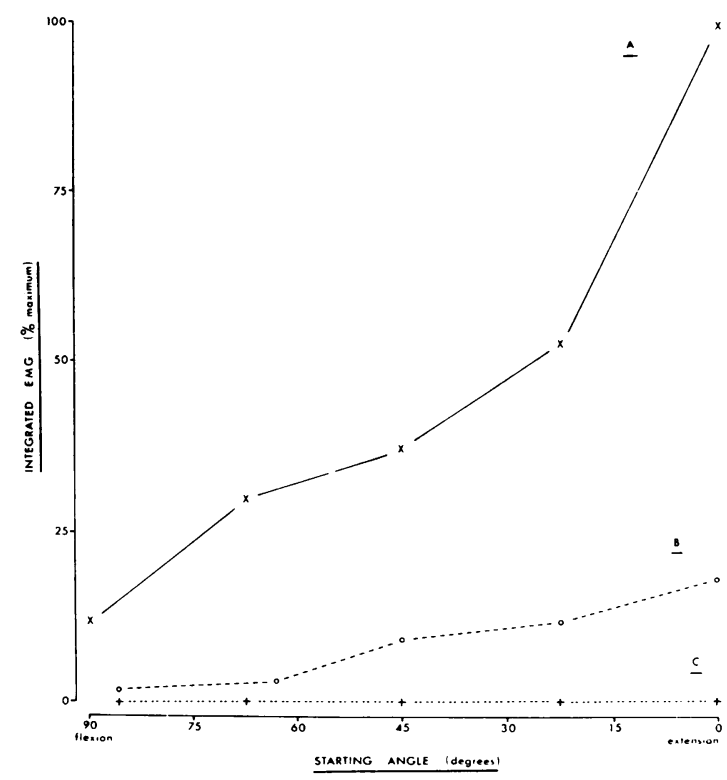

FIG. 8. Fatiguing of the stretch reflex. Three runs at comparable velocities. In the first run, $A$, the stretch reflex is prominent and position-dependence of the stretch reflex is apparent. In the second run, $B$, fatiguing has occurred and from the same starting angle, less EMG is obtained even though the velocity of flexion remains constant. The stretch reflex had completely fatigued by the time run $C$ was performed. No stretch reflex is obtained, even though the velocity of stretch is the same as in $A$ and $B$. 

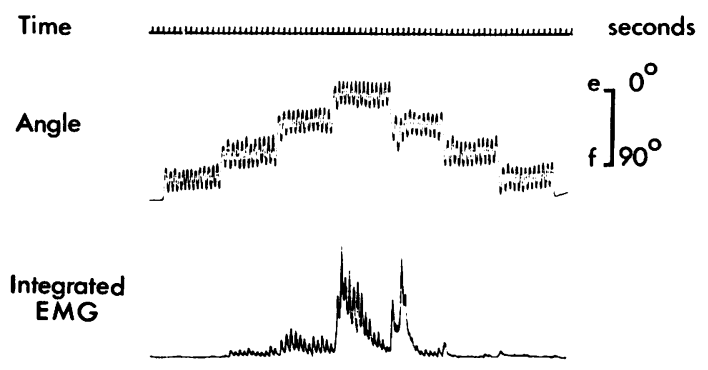

EMG

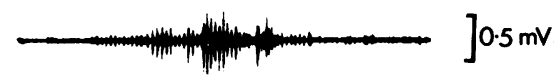

FIG. 9. Sinusoidal stretching. The limb is oscillating approximately sinusoidally through about $30^{\circ}$ at 1 c.p.s. As the point of oscillation approaches joint extension in a stepwise manner, the stretch reflex progressively increases.

suppression of the stretch reflex could still be demonstrated.

When the limb was moved sinusoidally at about $1 \mathrm{c} / \mathrm{s}$ through an angle of $30^{\circ}$, the stretch reflex was maximal when the limb oscillated about a point near full extension. The stretch reflex progressively decreased as the centre of oscillation was moved to a more flexed position (Fig. 9). The EMG activity was greater during the stretching phase of each cycle.

DURATION OF THE STRETCH REFLEX In some subjects the duration of the stretch reflex increased as the duration of the stretching movement increased. Despite this, the angle at which the EMG activity ceased became relatively earlier in the flexion movement as the velocity of stretch was decreased (Fig. 10), causing the stretch reflex to end before movement finished. In other subjects EMG persisted throughout the entire flexion movement, but did not continue when the stretch was maintained onces movement had ceased.

\section{DISCUSSION}

The stretch reflex in human spasticity has been shown to be determined by three factors: a velocity-: dependent factor of excitation, a position-dependen $\vec{E}$ factor of suppression, and fatiguability on repeated testing.

The first two factors are independent of fatigue of the stretch reflex. Once a constant level hap been reached, the magnitude of the stretch at any position of the knee joint was found to be thes resultant of the first two antagonistic factors.

That the stretch reflex in human spasticity increases with velocity of stretch has been noted. previously (Rushworth, 1960; Jansen, 1962; Shim azu, Hongo, Kubota, and Narabayashi, 1962: Leavitt and Beasley, 1964). Presumably this dependis on the velocity sensitivity of the primary spindtes ending, first studied by B. H. C. Matthews (1938]) and more recently by P. B. C. Matthews (196) The spastic stretch reflex has a marked velocipyo dependent dynamic phase but the stretch reflex dees not continue into a static phase during maintained stretch. Liddell and Sherrington (1924) noted thaㅡ. increasing the velocity of stretch in the decerebrate preparation produced a peak in the tension recopid which descended to a plateau as stretch was main-tained (static phase). The spastic stretch reflex thus differs from that of the decerebrate preparations because of the reflex response to maintained stretclo in the latter (Granit, 1958; Matthews, 1959).

Separate fusimotor control of the dynamic an $\$$ static properties of the primary ending has been ade $\overrightarrow{\overline{0}}$

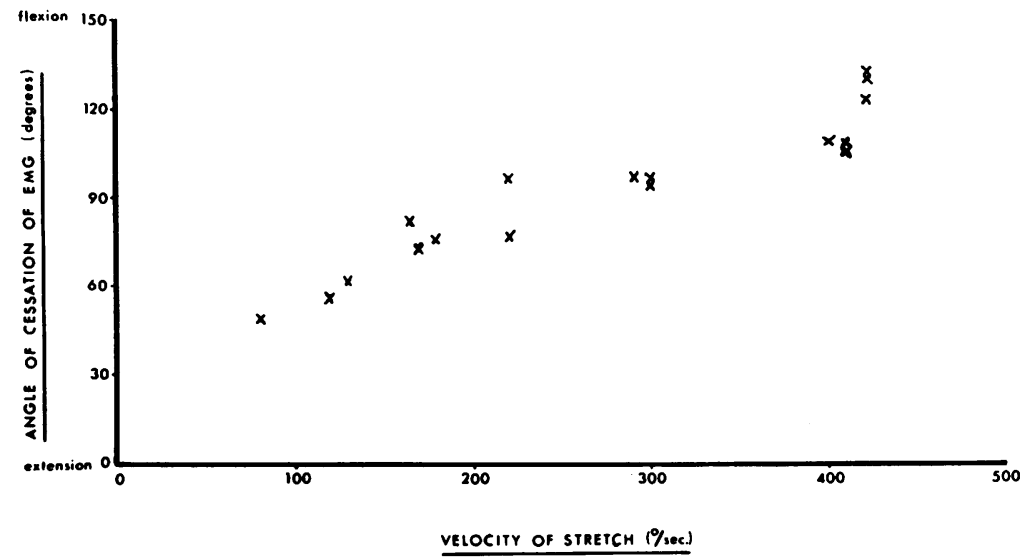

FIG. 10. The velocity of the stretching movement is plotted against the angle at which the EMG activity ceases. As the velocity of stretch decreases the EMG ceases at a progressively early angle in the stretching movement. 
quately established (Jansen and Matthews, 1962; Crowe and Matthews, 1964a, 1964b; Appelberg, Bessou, and Laporte, 1965; Bessou, Laporte, and Pagès, 1968; Lennerstrand and Thoden, 1968a, 1968b). In the spinal cat, Alnaes, Jansen, and Rudjord (1965) demonstrated activity in dynamic fusimotor fibres but were unable to show static fusimotor activity, and Fujimori, Kato, Matsushima, Mori, and Shimamura (1966) found a predominantly dynamic stretch reflex in cats rendered spastic by chronic spinal hemisection. It would thus be consistent to postulate release of dynamic fusimotor activity in the spastic state.

In the decerebrate preparation Granit (1958) showed that with stepwise increase in muscle length there was a concomitant increase in stretch reflex. In the absence of other modifying factors in spasticity, one would therefore expect the stretch reflex to increase when stretching an already partly stretched muscle. However in all but one patient the stretch reflex diminished as the muscle was lengthened, although the velocity of stretch remained constant. This suggests that the stretch reflex is inhibited by a factor depending on joint position or muscle length.

Ischaemic block of the lower limb reduced spasticity in our subjects, presumably because of a nonspecific reduction of afferent input to the spinal cord (Nathan, 1965; Dimitrijevic, and Nathan, 1967). Ischaemia sufficient to abolish position sense at the knee did not abolish position-dependent inhibition of the stretch reflex and the clasp-knife phenomenon. Moreover, Skoglund (1956) found in both spinal and decerebrate cats that natural and artificial joint afferent stimulation exerted only small and inconsistent effects on the monosynaptic reflex.

Since joint receptors are not responsible, inhibition of the spastic stretch reflex appears to depend on the length of quadriceps. There is no known way in which shortening of a flexor muscle is able to inhibit or disfacilitate its antagonist.

The Golgi tendon organ is not length-sensitive, but responds during active muscle contraction to tension and the rate of increase in tension (Jansen and Rudjord, 1964; Houk and Henneman, 1967). Houk and Henneman showed that tendon organs do not respond as a group to total muscle tension, but recruit individually on contraction of the relevant motor units. The Ib afferent input would thus increase progressively as motor units were recruited in response to stretch. The inference that tendon organs discharge synchronously at a threshold tension producing the clasp-knife phenomenon (Granit, 1964) is thus open to question. In spasticity, length-dependent inhibition outlasts reflex contraction and persists as long as the flexed posture is maintained, so that group Ib afferents cannot be responsible.

Both the primary and secondary spindle endings are sensitive to length. Presynaptic inhibition of Ia afferent terminals by Ia afferents has been shown to underlie the suppression of a monosynaptic reflex during the tonic reflex induced by stretch (Devanandan, Eccles, and Yokota, 1965) or by muscle vibration (Gillies, Lance, Neilson, and Tassinari, 1969). However the presence of a sustained tonic reflex in response to vibration in spastic man (Hagbarth and Eklund, 1968) and normal man (Lance, 1965; Eklund and Hagbarth, 1965) indicates that this mechanism is inadequate to explain length-dependent inhibition of the stretch reflex.

The rate of discharge of the secondary ending in response to stretch is less variable than that of the primary ending, resulting in a greater degree of length discrimination (Matthews and Stein, 1969). The reflex effect of group II afferents is known to be inhibitory to extensor motoneurones (Lloyd, 1943; Hunt, 1952, 1954; Eccles and Lundberg, 1959b) and could account for length-dependent inhibition of the spastic quadriceps. As the velocity of stretch is decreased, the dynamic group Ia input diminishes while the inhibitory group II input is little changed. Thus as the muscle is stretched at slow velocities, the stretch reflex may cease before the end of the stretching movement.

Job (1953) demonstrated tonic inhibition from the brain-stem of interneurones mediating spinal reflexes in the decerebrate cat, and this was later confirmed for interneurones of the flexion reflex pathway (Eccles and Lundberg, 1959a). Holmqvist and Lundberg (1959) localized this inhibitory bulbospinal tract to the dorsal part of the lateral columns. They demonstrated that its inhibitory activity was intense in the decerebrate preparation, but was abolished by spinalization which thus released the flexion reflexes.

It is therefore probable that the length-dependent inhibition described in this paper results from activity in group II afferent fibres from secondary spindle endings whose reflex effects are released from inhibitory supraspinal control by the lesion causing spasticity. The melting of the spastic stretch reflex which gives the reflex its clasp-knife character may then result from activity in the disinhibited group II afferent reflex pathway. Intense tonic inhibition of this pathway from the brainstem would explain failure to demonstrate such length-dependent inhibition in the decerebrate preparation.

From the foregoing it is apparent that the stretch reflex of the spastic subject differs markedly from that of the decerebrate preparation. Decerebrate 
rigidity cannot therefore be regarded as a suitable experimental model for human spasticity.

\section{SUMMARY}

The stretch reflex in the quadriceps muscle of spastic human subjects has been found to be determined by three factors, velocity-dependent excitation, length-dependent inhibition, and fatiguability.

On repeated testing the stretch reflex fatigued until a baseline level was obtained. As the velocity of stretch increased, the magnitude of the stretch reflex increased. On cessation of movement, reflex activity died away - that is, the dynamic phase of the stretch reflex was not followed by a static phase, such as that seen in the decerebrate preparation.

The magnitude of the stretch reflex was shown by both linear and sinusoidal stretching to be inversely proportional to the initial length of the muscle if the velocity of stretch remained constant.

Reasons are given for the view that this lengthdependent inhibition of the stretch reflex arises in secondary spindle endings, and that this inhibition underlies the clasp-knife phenomenon.

The authors wish to thank the National Health and Medical Research Council of Australia and the Adolph Basser Trust for their support of this work, and the Rockdale Lions Club for the donation of equipment. Mr. P. Neilson, Mr. K. Norcross, and Mr. N. Skuse have provided invaluable assistance. Graphs were drawn by Miss Susan Casey and illustrations prepared by the Department of Medical Illustration, University of New South Wales.

\section{REFERENCES}

Alnaes, E., Jansen. J. K. S., and Rudjord, T. (1965). Fusimotor activity in the spinal cat. Acta physiol. scand., 63, 197-212.

Appelberg, B., Bessou, P., and Laporte, Y. (1965). Effects of dynamic and static fusimotor $\gamma$ fibres on the responses of primary and secondary endings belonging to the same spindle. J. Physiol. (Lond.), 177, 28P-30P.

Bessou, P., Laporte, Y., and Pagès, B. (1968). Frequencygrams of spindle primary endings elicited by stimulation of static and dynamic fusimotor fibres. J. Physiol. (Lond.), 196, 47-63.

Brodal, A. (1962). Spasticity-anatomical aspects. Acta neurol. scand., 38, Suppl. 3, 9-40.

Crowe, A., and Matthews, P. B. C. (1964a). The effects of stimulation of static and dynamic fusimotor fibres on the response to stretching of the primary endings of muscle spindles J. Physiol (Lond.), 174, 109-131.

Crowe, A., and Matthews, P. B. C. (1964b). Further studies of static and dynamic fusimotor fibres. J. Physiol. (Lond.). 174, 132-151.

Devanandan, M. S., Eccles, R. M., and Yokota, T. (1965). Muscle stretch and presynaptic inhibition of the group Ia pathway to motoneurones. J. Physiol. (Lond.), 179, 430-441.

Dimitrijevic, M. R., and Nathan, P. (1967). Studies of spasticity in man-1 Some features of spasticity. Brain, 90, 1-30.

Eccles, R. M., and Lundberg, A. (1959a). Supraspinal control of interneurones mediating spinal reflexes. J. Physiol. (Lond.), 147, 565-584.

Eccles, R. M., and Lundberg, A. (1959b). Synaptic actions in motoneurones by afferents which may evoke the flexion reflex. Arch ital. Biol., 97, 199-221.
Eklund, G., and Hagbarth, K-E. (1965). Motor effects of vibrator muscle stimuli in man. Electroenceph. clin. Neurophysio 19,619 .

Fujimori, B., Kato, M., Matsushima, S., Mori, S., and Shimamura, MD (1966). Studies on the mechanism of spasticity followin spinal hemisection in the cat. In Muscle Afferents and Mot\& Control Edited by R. Granit. Pp. 397-413. Almqvist and Wiksell: Stockholm.

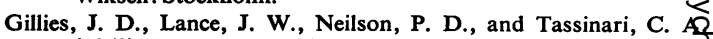
(1969). Presynaptic inhibition by vibration J. Physiol. (Lond.传 205, 329-339.

Granit, R. (1950). Reflex self-regulation of muscle contraction and autogenic inhibition. J. Neurophysiol., 13, 351-372.

Granit, R. (1958). Neuromuscular interaction in postural tone the cat's isometric soleus muscle. J. Physiol. (Lond.), 143, 387-402.

Granit, R. (1964). The gamma ( $\gamma$ ) loop in the mediation of musc tone. Clin. Pharmacol. Ther., 5, 837-847.

Granit, R., and Kellerth, J-O. (1967). The effects of stretch receptos on motoneurs nes. In The Neurological Basis of Normal and Abnormal Motor Activittes. Edited by M. D. Yahr and D. P. Purpura, pp. 3-28. Raven Press: New York.

Hagbarth, K-E., and Eklund, G. (1968). The effects of muscle vibration in spasticity, rigidity and cerebellar disorders. J. Neurot Neurosurg. Psychiat., 31, 207-213.

Holmqvist, B., and Lundberg, A. (1959). On the organization of the supraspinal inhibitory control of interneurones of variou spinal reflex arcs. Arch. ital. Biol., 97, 340-356.

Houk, J. and Henneman, E. (1967). Responses of Golgi tendo organs to active contractions of the soleus muscle of the cat J. Neurophysiol., 30, 466-481.

Hunt, C. C. (1952). The effect of stretch receptors from muscle $69 \mathrm{p}$ the discharge of motoneurones J. Physiol. (Lond.), 117, 359. 379.

Hunt, C. C. (1954). Relation of function to diamcter in affefents fibres of muscle nerves.J. gen. Physiol., 38, 117-131.

Jansen, J. K. S., (1962). Spasticity-functional aspects. Acta. neஹِ scand., 38, Suppl. 3, 41-51.

Jansen, J. K. S., and Matthews, P. B. C. (1962). The central controt of the dynamic response of muscle spindle receptors. J. Physif (Lond.), 161, 357-378.

Jansen, J. K. S. and Rudjord, T. (1964). On the silent period Golgi tendon organs of the soleus muscle of the cat. physiol. scand., 62, 364-379.

Job, C. (1953). Uber autogene Inhibition und Reflexumkehr'bei spinalisierten und decerebrierten Katzen. Pflügers Arch. ges Physiol., 256, 406-418.

Lance, J. W. (1965). The mechanism of reflex irradiation. Proc. Aust Ass. Neurol., 3, 77-82.

Leavitt, L. A., and Beasley, W. C. (1964). Clinical application of quantitative methods in the study of spasticity. Clin. Pharmaco Ther., 5, 918-941.

Lennerstrand, G., and Thoden, U. (1968a). Position and velocit sensitivity of muscle spindles in the cat. II. Dynamic fusimoto 9 single-fibre activation of primary endings. Acta. physiol. scand 74, 16-29.

Lennerstrand, G., and Thoden, U. (1968b). Position and velocit sensitivity of muscle spindles in the cat. III. Static fusimotor. single-fibre activation of primary and secondary endings: Acta. physiol. scand., 74, 30-49.

Liddell, E. G. T., and Sherrington, C. S. (1924). Reflexes in response to stretch (myotatic reflexes). Proc. roy. Soc. B, 96, 21 2-242.

Lloyd, D. P, C. (1943). Neuron patterns controlling transmissio of ipsilat:ral hindlimb reflexes in the cat. $J$. Neurophysiol 6, 293-315.

McCouch, G. P., Deering, I. D., and Stewart, W. B. (1950). Inhibitio of the knee jerk from tendon spindles of crureus. J. Neurophysiol., 13, 343-350.

Matthews, B. H. C. (1933). Nerve endings in mammalian muscle J. Physiol. (Lond.), 78, 1-53.

Matthews, P. B. C. (1958). The effect of the activity of the $\gamma$ motom neurones on the relation between tension and extension in the stretch refiex. J. Physiol. (Lond.), 140, 54P-55P.

Matthews, P. B. C. (1959). The dependence of tension upon extension in the stretch reflex of the soleus muscle of the decerebrat cat. J. Physiol.(Lond.), 147, 521-546.

Matthews, P. B. C. (1963). The response of de-efferented muscles spindle receptors to stretching at different velocities. J. Physiot (Lond.), 168, 660-678. 
Matthews, P. B. C., and Stein, R. B. (1969). The regularity of primary and secondary muscle spindle afferent discharges. J. Physiol. (Lond.), 202, 59-82.

Nathan, P. W. (1965). Two ways of reducing spasticity in man. In Control and Innervation of Skeletal Muscle. Edited by B. L. Andrew, pp. 196-203. E. \& S. Livingstone: Edinburgh.

Rushworth, G. (1960). Spasticity and rigidity: An experimental study and review. J. Neurol. Neurosurg. Psychiat., 23, 99-118.

Rushworth, G. (1964). Some aspects of the pathophysiology of spasticity and rigidity. Clin. Pharmacol. Ther., 5, 828-836.

Sherrington, C. S. (1897). On reciprocal innervation of antagonistic muscles. Third note. Proc. roy. Soc., 60, 414-417.
Shimazu, H., Hongo, T., Kubota, K., and Narabayashi, H. (1962). Rigidity and spasticity in man. Arch. Neurol. (Chic.), 6, 10-17.

Skoglund, S. (1956). Anatomical and physiological studies of knee joint innervation in the cat. Acta physiol. scand., 36, Suppl. $124,1-101$.

Walshe, F. M. R. (1919). On the genesis and physiological significance of spasticity and other disorders of motor innervation: with a consideration of the functional relationships of the pyramidal system. Brain, 42, 1-28.

Walshe, F. M. R. (1929). Oliver-Sharpey Lectures on the physiological analysis of some clinically observed disorders of movement. Lancet, 1, 963-968. 